\title{
Determinants of Economic Corruption in the Arab Countries: Dangers and Remedies
}

\author{
Kamel Touati \\ Department of Economic Sciences, Jendouba Faculty of Juridical, Economic and Management \\ Sciences - Tunisia \\ Correspondence should be addressed to: Kamel Touati; touati_kamel@yahoo.fr
}

Received 16 February 2013; Accepted 23 June 2013; Published 31 December 2013

Copyright @ 2014 Kamel Touati. Distributed under Creative Commons CC-BY 3.0

\begin{abstract}
The purpose of the present work is twofold. On a first stage, it aims at highlighting the corruption-related issues in terms of its definitions and different perceptions with respect to some economic theories, while stressing the specific factors lying behind the spread of such practice in the Arab countries. Actually, an emphasis has been put through this research on poverty, illiteracy, low incomes, poor governance, absence of strong powerful institutions and State of right and democracy, more generally the prevalence of a rent based economy, in addition to the impact of special socio-cultural beliefs and practices pertinent to Arab countries that constitute the major reasons leading to the aggravation of such blight throughout the whole region. Moreover, relying on an empirical study based on panel data model over the period 2005 to 2010, this paper tends to show that there does really exist a statically-significant relationship between the riser development size in corruption measured by the corruption perception index as a dependent variable, and the human development index, press freedom index and inflation rate as independent variables. On a second stage, some regulatory recommendations have been advanced within the scope of this work, likely to help fight against such a phenomenon by pointing out and curbing its subjacent latent roots, thus drawing these countries efforts, precautions measures and attention more on the rather preventive measures i.e. on economic policy and institutional reforms while stressing the role of taking further incentives.
\end{abstract}

Keywords: Arab Countries - Corruption - Institution- Panel data model.

\section{Introduction}

As a universal phenomenon, corruption is usually practiced on demand side (the corrupt) as well as the supply side (the corrupters), with outcomes not necessarily similar in size, order, and weight in all countries (Shleifer and Vishny, 1993). In countries all over the world, the embezzlements in particular, due especially to corruption, undermine all actions undertaken to improve their economic, social and environmental well-being, and hinder efforts oriented to reduce poverty
(Lambsdorff, J. G., 1999). In the Arab countries, corruption is a wide-spread phenomenon, which affects economic development (World Bank, 1992), resulting in serious moral and political concerns. In addition, corruption constitutes a subject of common concern to these countries as it compromises the good management of public affairs, perturbs markets' wellfunctioning, and distorts the compliance with the requirements necessary for an open and transparent competition, based on price and quality. Noteworthy, however, corruption also entails a waste of 
development-allotted resources - already not plentiful in several Arabic countries whether derived from assistance, or other public and private sources, with heavy outcomes and implications on the whole economy (Frisch, D., 1996; UNDP, 2002).

Yet, one might well wonder, in this respect: what does corruption refer to? What are its real causes with regard to Arab countries? Why is it more wide-spread in certain Arab countries than in others? What are its empirical determinants?

In an answer to these questions, we reckon it convenient to initiate the first section of this research by setting the definition relevant to corruption, simultaneously with an exposition of the global perception ways of this phenomenon based on certain economic theories and facts. As for the second section, it deals with the Arab countries pertinent corruption with a special reference to their cultural specificity, the prevalence of a high illiteracy rate, weakness of income, lack of democracy, while emphasizing the economic reasons lying at the origin of development of this plague. In the third part of this work, an empirical attempt is made to highlight the relationship existing between certain independent variables, namely: human development index (HDI), inflation rate (INFLA), and index of economic freedom (IEF), on the one hand, and the expansion of corruption measured by the corruption perception index (CPI) as the dependent variable on the other, for the purpose of assessing and verifying the relationships established in the preceding section. Regarding the last section, it is dedicated to advancing certain proposals and measures we reckon useful to fight against such a plague as perceived in the Arab countries.

First thing to start with is defining corruption.

\section{Section I) What is Corruption and How is it Perceived?}

\section{A-Definition of Corruption}

Corruption is a general term that covers various aspects of authority abuse, and designates a set of bad practices ranging from fraud, nepotism, collusion to insider dealing or trading and even extortion. Yet the most usual and omnipresent form is doubtless bribe ${ }^{i}$ and bribery. According to Transparency International (TI): "corruption consists in the abuse of delegated power for private ends and purposes" (TI, 2002)ii. This definition allows for isolating three major component elements of corruption: 1-the abuse of power; 2- for private ends and purposes (thus not necessarily benefiting the person abusing power, but including as well members of his closer family or friends); and 3-a power received in delegation (which can therefore emanate from the private as well as from the public sector). Still, the definition provided by the European Council is even more precise: "corruption is an illicit remuneration or any other behavior towards the persons invested with responsibility in the public or private sector, which violates obligations which they have by virtue of their status as State agents, private sector employees, independent agent or another context of similar nature and which aims at procuring undue advantages of whatever nature, for themselves or for a third party ». In turn, the World Bank distinguishes two types of corruption reflecting differences in terms of scope and frequency of practice: large-scale corruption and small-scale corruption. The first kind is often less frequent. Despite its prevalence at national or international levels, as well as in the spheres of private sector along with those of civil society organizations, this corruption is mostwidely persistent in the public sector, where political decision-takers making, creating, and applying laws, use their official position to promote their wellbeing, their status or their personal power.

Thus, the large-scale type of corruption concerns above all the relationship between companies (or, more general by networking ways and interest groups) and the State (political power). Hence, it pertains to i.e. trust of authorities and their respect (Paldam, 2002). However, corruption is said to be small in scope when it is practiced by performers, often called minor officials, who have no decision- 
making power. It is often sustained by small bribes as support. Yet, there are no clear demarcations distinguishing between the large and small scale types of corruption. It is also worth noting that certain corruption practices can be simultaneously sited between both the large as well as the small scope of corruption (UNDP, 2003).

At this junction of events, it is worth asking: Is this phenomenon perceived in the same way in all the countries?

\section{B) How is Corruption Perceived?}

Given the fact that corruption is so enormous and sensitive issue, it is often controversial and can be approached differently from one country to another. Actually, corruption possesses connotations at the same time very different and subjective according to period and place of its use. This difference takes place with regard to the perception of social rationality or irrationality of the phenomenon. Thus, according to the (neo)classic economic theory, corrupt practices and behaviors do have a "rationality" behind them as they allow the corrupters and the corrupt certain satisfactory equilibriums in time. According to this theory, what matters most is the individual's utilitarian conception (or homo economicus), considered to be motivated by the search or quest for interest he/she is always capable of expressing in terms of calculable gain, by responding to incentives in the same way as a robot, an automaton, etc. In this way, the (neo)-classic economy appears to analyze corruption with regard to individual behaviors in terms of search for rent (rent-seeking in public choice theory). In fact, the very existence of rents is related to market distortions. In a first place, it is actually the State which, by maintaining artificial monopolies, creates and enhances opportunities for rents. However, even in a market economy, rent opportunities (thus of corruption) remain, due not only to the fact that certain monopolies, dubbed as "natural" cannot be eliminated, but also to the fact that in order for the market to operate and function "properly" or smoothly, certain rules of game, supposed to prevail, which have to be respected (Krueger, Has. O., 1974; Coolidge, J. and Rose-Ackerman, S., 1997) ${ }^{\text {iii. }}$. Nevertheless, such an individualistic liberal approach as applied to analysing corruption includes penalty, sanctioning, and punishment, while highlighting certain factors relevant to the country's institutions quality. So, this theory can give rise to an inflexible intransigent position vis-à-vis corruption through a zero tolerance, along with a very strict moral discourse. Nevertheless, it can also lead to a much more pragmatic attitude, admitting as a result that it is not possible to eradicate corruption nor even to contain it, and that one can only aim at mastering it and restricting its negative effects (F. Talahite, 2006).

Still in this context, but in disagreement with this classic theory, a number of authors prove to be more skeptical about this subject, considering corruption as something inevitable whether owing to us the generalized extortion or to its customary frequently-habitual practice (Rocca, J.-L., 1993; Moody-Stuart, G., 1997; Nadgrodkiewicz, A., 2009).

Other authors, though, scarcer and scarcer nowadays, have gone even further by maintaining that a certain extent of corruption is even desirable for two main reasons. Firstly, by playing the role of making a bonus for each task achieved by the agent, the additional cost turned over by the latter is likely to entice him to accomplish much more and further work. Secondly, corruption enables entrepreneurs to by-pass an inhibitive administration (Leff, 1964). Thus, corruption allows, for instance, to "grease the wheels" of a stiff administration (Bardhan, 1997). By means of illustration, corruption turns out for a company, to be transformed into such a frequently usual commercial practice that it allows to accelerate the services it is entitled to in a bid to avoid penalties (deserved or not) by the authorities, to eliminate the bureaucratic obstacles or to ensure the guarantee of lucrative public markets. According to this theoretical approach, within the context of the developing countries, certain invasive regulations, 
corruption may contribute in increasing economic efficiency. This belief is supported by the theory which, in an environment dominated by the preexistence of distortion, generative policies in which the pareto-optimum is impossible to achieve, stipulates that the corrective policies, in fact failing, allow to reach a second best. Consequently, in countries where wages are low and in which goods and services are not sold at their real value on highly regulated markets, corruption would restore the prices mechanism and improve the allocation of resources (Lui, 1996).

Even though, at a later stage, Honlonkou (2003), on following the tracks of other authors, has attempted to demonstrate the falsehood of the last argumentation - by arguing that what can be considered as a short-term advantage thanks to bribery, harmfully affects businesses by giving birth to an unfair competition and incurring additional costs and engendering negative external effects by weakening the legal rule and regulations, aggravating bad governance and reducing efficiency as well as productivity in the economyiv- it appears according to the general perception, that the attitude towards corruption fluctuates between intransigence, tolerance, and even desire.

Ultimately, more than any other phenomenon, corruption can be considered as a "purely social fact", in so far as it simultaneously refers back to economic, political, legal, and social areas or matters and so on (Durkheim, 1937). As such corruption is not an entirely "white" problem, regarding which the majority of public opinion as well as the elite do not firmly support condemning attempts of the seemingly tolerable acts, nor is it "wholly black" in its entirety, which indicates that a particular action is such as a consensus exists within the greatest majority of opinions along which the elite to condemn and sanction it in the name of principles: still, we are found face to a range of nuances, i.e. "grey corruption", highlighting that certain elements usually the elite do want to see the act repressed, while others do not; public opinion, in its majority may then turn out to be ambiguous (Bresson J.C., 1997). This normalized illegality has gained ground owing to the widening discrepancy gap established between two orders: 1-the symbolic order: Max Weber's administration and policy as a space in which money plays no role, and 2-the elites order of concrete practices : the role of money in politics and the osmosis between the political and administrative sphere. This situation case is most often reflected in the way corruption is described in certain languages (ibid, 1997). Similarly, the functions of corruption, its forms, amounts put out and involved actors might be discovered to be so different that the phenomenon remains hardly unified and identifiable. As matter of fact, its outlining vary according to the cultural, economic and social environment on the one hand, and to the actors' behavior belonging to these societies on the otherv. With respect to the Arabic language, it has, in turn, a certain number of terms describing practices which may or not be considered as corrupt. Should it be true that "fassad" (corruption or «decay») is often attributed with a negative connotation, other commonly used terms are not necessarily pejorative, and are liable to interpretation. For instance, the word "baksheesh" (small payment) is considered as a payment to facilitate the execution of an act, so is it a tip? The "wasta" (favoritism), which soaks all the Arab countries culture, is an inappropriate appeal to relationships, or is it a justifiable contact establishment?

Such ambiguities make corruption an emotional subject in the Arab countries, often impeding any constructive debate on the way of fighting its harmful effects. As a proof, debates on corruption most often degenerate into sterile squabbles stirred by national pride, along with a country's bad will to admit that its corruption-related issues may be worse than its neighbors. As a matter of fact, countries where corruption is most intrusive feel as pointed out to by others and even if they understand the extent to which corruption can be harmful, still consider themselves hurt by the charges directed to them. In theory, the fact of highlighting a given country shortcomings can instigate the competition 
spirit and motivate the country to try hard and make every effort to become less corrupted. In practice, however, with regard to Arab countries, the feelings of resentment often have the upper hand and hamper any constructive progress (Nadgrodkiewicz, A., 2009). More ironically, these types of illegal payments often fall under more respectable names describing them as commissions or counseling expenses though it is actually clear that they simply designate bribes. Consequently, it seems more useful to formulate debate regarding the corruption questions around such terms as "strengthening the integrity" or still "improving governance". Such a strategy allows dealing with corruption as a structural problem rather than a political one, thus avoiding attributing the stigmas of corruption to the one or the other.

In Arab countries small-scale corruption (bribe) is deeply anchored in the political and economic systems, and has ceased to be recognized as an inappropriate behavior. This common consent regarding this type of corruption as being something "normal" is dangerous, since it helps consolidate a culture of bribery and strengthen corruption as an institution. Should bribe providers and its receivers no longer view bribery as a fault but rather as an admittedly recognized standard, legal rule then, turns out to be fundamentally weakened. This is exactly what actually takes place in most Arab countries. This situation is particularly true in an area where talking openly about corruption remains paradoxically a cultural taboo.

Further to considering corruption as a moral problem, and for the sake of fighting it in an effective way, it would seem necessary to consider it as an institutional problem which imposes additional costs on business, reduces efficiency, hinders development, and harms society in general.

However, such a definition and perception of corruption, lead us to pose the following questions: What are the causes of corruption with respect to the Arab countries? If corruption is a universal phenomenon, occurring at a more or less large scale in all countries and cultures, why is it then more prevalent in the developing countries, above all in the Arab countries? Do prevalent conditions provide it with more incentives?

Although, a standardized approach does not fit perfectly well to describe the forms, and especially the causes of corruption prevailing in all Arab countries, - given the fact that the nature, major sources, manifestations, aspects, and scope of corruption often vary among between these countries and their respective institutions which, still present certain similarities -; it is also worth recognizing that in general, the causes of corruption are highly identical in these countries. One might well wonder: How does it come?

\section{Section II) The Complex Causes of Corruption in Arab Countries}

Until the 1980s corruption had been apprehended as a social phenomenon, of political sciences or from criminal-law perspective, ever since, however economists have tackeled such a subject. So, it is recommended, according to them, to underline the first stage necessarily for having begun to deal with or approach the corruption issue which lies in recognizing it not exclusively as a political problem. The source of corruption is not merely a handful of governmental high-ranks, or responsible personalities or figures, or dishonest civilstate employees; and the fact of simply substituting them would not, by any means, put an end to such a practice. In fact, corruption does not prosper due to, or at least, not exclusively because of defects in certain person's character. What really more matters is the environment which secures impetus and favorizes motivation for a corrupt behavior. Or, on examining the literature, one can depict certain factors appropriate to certain countries, particularly the population size, religion, cultural dimensions, and natural resources, which seem to be positively correlated to the omnipresence of corruption (Cheryl, W. Gray and Kaufmann, D., 1998). These results are even further supported by certain empirical studies (Andving et al., 2000). It is obvious that in Arab countries corruption is a common issue, whose level 
has been heightened even more, throughout different degrees, with diverse causes varying from one country to another. Briefly, corruption represents a symptom of complex causes which can be classified into four major categories, namely: causes related to supply and demand, institutions relates to ones, others are political in nature, while others are of cultural nature.

For a better understanding, the latent reasons lying behind a corrupt behavior as pervading in the Arab world, most common among which is the offer of bribes, it turns out to be necessary to catalog it as a simultaneously economic (demand and supply), institutional, political, and cultural problem (Andving et al., 2000 ; Luo, 2004).

On the demand side, we find a wide range of lugubrious socioeconomic factors such as poverty, illiteracy along with a high unemployment rate. According to the International Labor Organization (ILO), with a percentage of $16 \%$ in 2011, the average unemployment rate prevalent in the Arabic world is already amongst the highest along with other regions worldwide. Similarly in 2010, in which the registered rate was also one of the highest at the world level: $13.82 \%$; - even $18.1 \%$ if we exempt the Gulf countries, i.e. the equivalent of 18 million unemployed persons. For instance, this average rate reached $14.4 \%$ in 2005, compared to $6.3 \%$ in the rest of the world (Arab Labor Organization, 2012). As for poverty, the situation is not better. In 2009, 140 million persons lived under the poverty line, that is about $19 \%$ of Arabic population lived with less than 2 \$ a day, which would represent $60 \%$ more than the average prevalent in Latin America, for instance. As regards to the national poverty rate, designating the percentage of population living under the national poverty linevi, it oscillated during that same year between 27 and $30 \%$ of the population in Syria and in Lebanon, $39 \%$ in Egypt, about $50 \%$ in Sudan, even more by reaching the threshold of $58 \%$, as it is the case in Yemen. Even though these statistics reflect very diverse circumstances, the situation, in its entirety, risks to becoming even more explosive owing to the currently prevailing "democratic transition". It is estimated that the region's active population, which was counted approximately 100 million workers in 2000 , would soar up to 185 million by the year 2020. Regarding illiteracy, which could stand as another source of corruption, Arab countries have difficulty in curing such a plague. Actually, illiteracy affects about 30 $\%$ of people aged 15 years old and more, making up about 60 million adults. At the same time, these countries record the lowest adult illiteracy rate in the world, about $70 \%$ of the Arab population of 15 years old and more. This rate is evidently lower than the world average (84\%) as well as that relevant to the developing countries (79\%) (UNESCO, 2009).

An ultimate demand-associated factor corresponds to the presence of strong income disparities among members of the same community; this situation is heading for nepotism by depriving groups most vulnerable to work (UNDP, 2011). The Arab countries Gini-revenu index, in Arab countries, which measures the distribution of income or consumption expenditure among individuals or households, observed within a certain country and with a perfectly equal distribution, rose up to $64,3 \%$ in the Comoros in 2004 for instancevii.

These are some of the demand-pertinent causes, so what about supply-pertaining ones? Once more, they are numerous. One of the most spread causes relevant to the public sector is to the employee. Salaried people are terribly under-paid in certain countries. And their salaries are too low especially with respect to the private sector. Such low incomes induce a certain number of civil servants towards corruption. This is noticeably clear particularly with respect to the high ranks of government officials and provides even a better excuse to low-level employees and workers to do so even more, whether they are employed in the public or the private sector. Thus, the greater the differences in compensation between public service and private sector are, the more important the temptation to illegally bridge or reduce these discrepancies is, and, therefore, the 
more the corruption opportunities become, the greater motivation becomes to join the public service. As a matter of fact, the administrative services undergo and are liable to, a permanent pressure from the part of the political authorities, be it, clan or family ones, which limits the application of the meritocracy principles. The practice then, which consists in buying a function in the administrative sector in a bid to perceive better "bakchichs" tends to spread over (Wade, 1982). This also finds an explanation in the assertion of Klitgaard, according to which the low rate of the public-service remunerations largely accounts for the everyday acceptance of small corruptions (Klitgaard, 1989).

More generally, and by means of comparison with other developing or emerging regions, incomes in most Arab countries (exception made for the Gulf countries) discovered to be much lower. Actually, in 2008, the average Gross National Income per capita (GNI/capita) (at purchasing power parity (PPP), in \$), in the Arab countries was merely equal to 7.861 , against $10.642 \$$ in Latin America and the Caribbean islands, and $11.462 \$$ in Europe and Central Asia. The world average is of $10.631 \$$. This goes without even mentioning the developing countries, with a very high human development, which equals $37.225 \$$, while in those with a high human development this is raised to 12.286 $\$$. With regard to the third reason leading to a rise in corruption, it has to do with the scarcity of public goods' supply in certain Arab countries, culminating in creation of long queues. The longer these queues are, and the more the targeted concerned property is indispensable (e.g. an accommodation, a telephone line for a company, hospital vacancy, a scholarship grant, water for irrigation, etc.), the more the economic agents are ready to resort and have recourse to distorted ways to have access to such services by offering bribes to persons in charge in a bid to come in a first position before anyone else. This state can be approached through the facility index to engage in business entrepreneurship. Unfortunately, such a business climate constitutes a domain in which these countries exhibit inferior low results and figures ${ }^{\text {viii. }}$

The rent-based economies characterizing certain Arab countries, in turn, do enhance corruption, as the natural resources lying at the origin of these rents are sold at prices appreciably higher than their actual cost. So the sale of concessions is usually accompanied with bribery payments. In economies strongly dependent on oil rents, mainly the Gulf countries, Algeria and Libya, the government can play the role of a generous donor requesting no taxes or other rights in return. Similarly, these regimes safeguard their sustainability and perennity in power through the generous financing of organized-repression agencies and media financed thanks to this oil basket. The most striking example is that of Iraq. After its invasion by the United States of America (USA) in 2003, corruption played a great part in squandering its resources; especially the oil-related ones (Salah Al-Nasrawi, 2008). According to a report published by the Government Accountability Office (GAO) in May, 2007, the quantity of oil daily sold by means of smuggling since 2003 would be estimated at a value ranging from $\$ 5$ million to $\$ 15$ million, i.e. the equivalent of 10,000 up to 300,000 barrels a day, with the complicity of corrupt officials in charge being established (Beehner, L., 2007). A few weeks following occupation, the decay began to spread as never was before, in such a way that the TI classified Iraq in the second rank on the list of 180 countries affected by corruption in both the public and private sectors (RSDH, 2009). In fact, bribes collected during the signing and conclusion of large contracts in these rentbased regimes simultaneously serve to the personal enriching of the elite members as well as to the setting up and of customerredistribution networks, which allow the political authorities to remain in power by buying supports. These informal networks, along with the links and alliances they help establish, take on more importance especially with the prevalence of large ethnic, religious and regional divisions in the Arab countries. In this respect, the micro-economic researches dealing with 
the causes of corruption, traditionally relying on contributions brought about by the information economy and the principalagent theory, highlight that corruption opportunities highly depend on the importance of rents placed in the hands of civil servants, due to the latitude they enjoy to distribute these pension rents and their lack of the sense of responsibility towards the society (Klitgaard, 1988).

It is also worth noting that, in the Arab world, corruption is not exclusively the result of the economic factor, but also the by-product crucially critical element with a deterministic impact: the political situation. In fact, the political aspect, in turn, incites corruption. Moreover, it is not easy in the Arabic universe to separate the political power and the economic one, as they must often converge into either a similar trend, a duly-assumed long-lasting alliance, or into an objective consensus on a common ground of real interests. Even though the political situation, which the Arab world is experiencing differs proportionately from one country to another, it remains, overwhelmingly tyrannical in nature, even chaotic at certain times, owing to the triggered "Area-spring" - related changes. Noteworthy, in this respect, the Arab political systems, marked by a democracy defect, helps favorise abuse of public power for personal-interest purposes, so publicmoney misuse turns out to be normal practice conforming to the current trends and processes, or even necessary for the sake of guaranteeing the regime sustainability in the Arab countries. In such cases, corruption obviously reveals an imperfection pertinent to the political system which had already been obscured, and stained by public authorities (Bresson, J-C., 1997). Structural corruption is, thus, a part of a systematic State policy. It is distinguishable from conventional corruption in which the author acts behind the administration back in fear of law. In fact, structural corruption is one of the main obstacles impeding reform in the Arab countries, given the fact that it is systematically used to sabotage political and civil activities and create classes, which take advantage from the status quo. Furthermore, by controlling the entire levers of power, the Arab countries leaders can handle the judicial system to eliminate and put down the opponents to their regime, their opponents and even dissidents. It jointly with the surge of "under silence" passed occurring corruption whereby the close partisans of the regimes underway ready, are authorized to profit from their posts and exploit them to grow rich illicitly, and the threat of "a law enforcement or suite" against them guarantees them total allegiance. It is also worse noticing that the manipulation of law paves the way for the economic kind of corruption, as a natural outcome of the political corruption. Those who falsify the results of elections alter and distort law acquire tentatively attractive instruments for forgery and for serving their own. Such a situation induces business entrepreneurs and undertakers to complain about the fact that persons in power monopolize the major economic domains, either directly or "jointly" with eminent businessmen (UNDP, 2004). All this highlights that the dominant political and legal structures under way in these countries make it difficult to distinguish between conventional corruption (abuse of public power for personal- interest ends) and weaknesses inherent to the system.

To the aforementioned causes of this plague, one might well add another corruption explanatory factor pertinent to certain distortions prevalent in the Arab local cultures, which helps induce these more vulnerable populations to be affected by this scourge. For instance, the strong family ties and the tribal allegiances are important causes of corruption in several countries of the region. Actually, civil servant allegiance to his/her family, his/her tribe, makes him/her more vulnerable to corruption. This is partly due to the fact that the Arab system of traditions is based on strong ties and parental relationships, and highly cherishes loyalty towards the head of the family and family obligations (Heidenheimer, A-J., 1989). Another very serious cultural distortion, rather specific to the Gulf countries, is the well-anchored and deeply rooted feeling of proprietorship. Most often in these countries, families in power detain and hold the country 
resources. Nowhere else in the world do leaders detain the country's wealth and resources. It is then an important factor, a cultural one which renders these countries more vulnerable to distortion (Hisham A., 2009).

Worth recalling also is the institutional domain in which the judicial system is not independent. In certain Arab States, according to the law itself, the land and its natural resources belong to the country's leader, without distinguishing, in this respect, between the leader's public and private aspects, with the ordinary citizens, private property being considered as a donation granted by the leader. In such a case, it is difficult to talk about corruption with regard to governance, since whatever the leader does would be considered as part of arranging the leader's own properties (UNDP, 2004).

To sum it up, one might well deduce, from what has already been mentioned, that the phenomenon of corruption, which pervades over the whole Arab world is primarily caused by economic phenomena enhanced by improperly bad governance and weak institutions (Broadman and Recanatini, 1999; Gerring and Thacker, 2005). This situation reflects the Arab States collective failure to deal with such crucial questions as progress in matters of human development and popular representation, the incapacity to offer citizens a decent life, be it in terms of frequently needed elementary necessities of everyday life, human rights, or both together, which has resulted in the over flow of an oppression, suffering, and instability climate. This massive corruption, with its various aspects, is also conspicuously visible to the normal citizens, as well.

At this level, it is worth asking: What about the underlying empirical analysis fit for such a literacy overviews?

\section{Section III) Empirical Study}

The goal of this section is to evaluate the effect of some variables on the generalization of corruption in the Arab world. Empirically, to estimate this relation, we use a panel data model in which the CPI is considered a dependent variable, and HDI, INF, and IEF independent variables. Data is available over the period 2005 to 2010. Hence, our panel-data regression model is specified as follows:

$$
C P I_{i, t}=\beta_{0}+\beta_{1} H D I_{i, t}+\beta_{2} I E F_{i, t}+\beta_{3} I N F_{i, t}+\varepsilon_{i, t} \text { where } C P I \text { is the corruption }
$$

perception index ; HDI : human development index ; IEF : index of economic freedom ; INF: inflation rate and $\varepsilon_{i, t}$ is the error term; $i$ : represents the country, $t$ : represents time variable,

$$
\text { with : } i=1 \ldots 21 \text { and } t=2005 \ldots 2010 \text {. }
$$

The corresponding results of regression are presented in table 1 below. 
Table 1: Results of the Panel Data Regression Model from 21 Arab Countries

\begin{tabular}{|c|c|c|}
\hline \multicolumn{3}{|c|}{$\begin{array}{c}\text { Dependent Variable : CPI } \\
\text { Reference period : } 2005-2010\end{array}$} \\
\hline $\begin{array}{l}\text { Independent } \\
\text { Variables } \\
\end{array}$ & $\begin{array}{l}\text { Fixed } \\
\text { effects Model }\end{array}$ & $\begin{array}{l}\text { Random } \\
\text { effects Model }\end{array}$ \\
\hline Const & \begin{tabular}{|c|}
3.918013 \\
$(1.26)$ \\
\end{tabular} & \begin{tabular}{|c|}
-3.299802 \\
$(-2.30)$ \\
\end{tabular} \\
\hline HDI & $\begin{array}{c}-7.448373 \\
(-1.49) \\
\end{array}$ & $\begin{array}{l}4.077001 \\
\left(2.51^{* * *}\right)\end{array}$ \\
\hline INF & $\begin{array}{l}-.0241592 \\
\left(-2.34^{* * *}\right) \\
\end{array}$ & $\begin{array}{l}-.0264639 \\
\left(-2.56^{* * *}\right) \\
\end{array}$ \\
\hline IEF & $\begin{array}{l}.6450186 \\
\left(3.02^{* * *}\right)\end{array}$ & $\begin{array}{l}.6739809 \\
\left(3.57^{* * *}\right)\end{array}$ \\
\hline \multicolumn{3}{|c|}{$\begin{array}{l}* * *: \text { significant at } 1 \% . \\
0 \text { :t-statistics } \\
\text { Hausman Test: } \\
\text { Chi2 }(3)=5.79 \\
\text { probability }=0.1223\end{array}$} \\
\hline
\end{tabular}

The estimation of our panel data model over the period 2005-2010, for a sample of 21 Arab countries, indicates some results compatible with the theoretical presuppositions advanced in our analysis. The regression coefficients are statistically significant for HDI, IEF, and INF. The positive sign of the coefficients of the independent variables indicate positive effects, which means when HDI and/or IEF rise(s), CPI do (es) also, and vice versa. Why? This result may demonstrate an important relationship between economic freedom, human development, and the positive social and economic values such as per capita income, economic growth rates, and the reduction of corruption.

However, the negative coefficient means that if INF rises, the CPI decreases (corruption increases) and vice versa. This result demonstrates that inflation causes corruption in the Arab countries.

Finally, the Hausman test, shows that our model is a random effect one.

\section{Section IV) Some Recommendations Advanced to Fight Corruption}

Corruption as prevailing in Arab countries represents the symptom of fundamental economic, political, cultural, and institutional causes. For an effective remedy to such a disaster to yield positive results, it is necessary to combat the relevant underlying causes. In fact, the effort of these countries has to concentrate mainly undertaking preventive measures, i.e. reforming the economic policies, institutions, and incentives, otherwise, any attempt to improve the application of anticorruption legislation by resorting to the police, to the institutions that preserve and defend business ethics and deontology or any other state-based special supervisory boards and organisms within the State would be doomed to failure. If eradicating corruption goes through a deep economic reform of the laws and mechanisms relevant to an effective sensitization and transparency in matters of governance, then a radical reform of the political architecture seems indispensable to master the structural corruption which the Arab countries undergo and suffer from (AHDR, 2003). Putting an end to corruption also entails, in addition to an economic reform, a deep political reform, a change of laws active and sensibilization as well as transparent governance. Putting an end to corruption requires, in addition to a thorough economic reform, a deep political reform, the setting up of laws and active mechanisms of empowerment, as well as transparent governance. From a strictly economic point of view, fighting corruption requires its examination from an offer and demand perspective. Most often, the responsibility of corruption is exclusively 
put on civil service employees who accept a bribe. In fact, public sector employees represent the demand side of corruption, and obviously carry the burden of responsibility, but they are not the only ones to be blamed. Indeed, as specified earlier, two sides are involved in the act of exchanging a bribe: for exact case in which a bribe is accepted, it needs to be offered at first. It is the offer-side of corruption. What is lacking in the numerous corruptionfighting initiatives in the Arab world (e.g. in Egypt and the Palestinian territories), is the fact of simultaneously attacking convergence of both the supply and demand parties of corruption. In the debates accompanying a number of these initiatives, we frequently witness companies accusing the governments and vice versa without reaching a common understanding of the problem. Nevertheless, the corruption curbing can by no means be successful unless preventing such corrupt practices does make a sense to the economic plan for stakeholders in their entirety, including companies. This can only be reached by creating better institutions conducting standards of behavior, which make the corruption-incurred costs soar to such a point that it would not deserve more the risk we take. The business-conduct principles designed to face and stop corruption require such a practical tool to make companies participate in setting up a better governance.

Some of the major economic-policy performances reform measures likely to help reduce, with no recurrent ambiguity corruption could for instance, the reduction of customs duties along with other barriers relevant to international trade; unification of the exchange and interest rates as determined by the market; elimination of subsidies to companies; reduction of regulations; bonds of license and other obstacles for companies and new investors; the dismantling of monopolies and privatization of public assets; along with an application taking into account what has already been learnt about the harmful political influences, and that there should be certain means whereby to put an end to evil thanks (corruption) to accurately innovative means brought to the procurement and submission methods. Finally, one last fundamental element likely to serve as a subject for a prospective stage of studies on corruption and its repression, measures might be the fact that specialists have to look for methods necessary for collecting and distributing information susceptible to produce the fastest and the most direct effects. For instance, the notation-card method as applied by an NGO (Non-Governmental Organization) of Bangalore (India), requires users to note down the service-providing local bodies and organisms and has already resulted in the dismissal of certain state employees, improvement of the service provision quality and dwindling done in corrupt practices. The collection and the broadcasting of data, the extremely varied costs of lunches offered by the State in the schools sited in different localities within the same country, have entailed reforms not only relevant to these localities, but also to others. The setting-up of a free press with certain freedom degree margins, the establishment and the preservation of restrictive laws on the defamation likely to protect the state policies and employees must be fought to protect the freedom of expression and information for citizens. Actually, no matter how difficult and imperfect the collection of data on corruption and the distribution of the obtained results will be, one could not highly indulge on the importance of such activities. The practice of secrecy has helped the elites and politicians keep corruption concealed in various countries. The methodical analysis, presentation, and distribution of data can effectively contribute in making the population more sensitive, creating dynamics in favor of relevant reforms and to widening our limited understanding through the success and failures of the measures undertaken to fight against corruption. The reform of the State institutions can include restructuring public service, the improving of budgeting, reforming financial management and the tax authorities, as well as the strengthening of the legal and judicial systems. Such reforms have to modify the state pertaining structures and procedures, by promoting competition and internal incentives in the public sector, and by reinforcing the 
weights as well as the internal and external counterweights. To close the present work, the scrupulous and transparent application of law, such as the prosecution of certain corrupt "great" men, can also be useful. The list of possible anti-corruption measures does not stop at this junction. It is advisable to choose the major measures fit for implementation, while considering the potential capacities of execution available in the country, at the launch of the anticorruption campaigns and its aftermath. As systematic corruption is deeply rooted, by definition, it is necessary to act energetically - a gradualist approach would yield to no big results. Since corruption fighting initiatives and opportunities have only recently taken place in numerous countries, it is important that reformists immediately overtake the initial general principles usually expressed in the papers dealing with this plague and protest unlike the practical notices adapted to their case. After a meticulous evaluation of the relevant country situation, it would seem necessary to formulate exact tips on the policies necessary to be followed and institutions to be reformed. For instance, the technocrats have begun to realize that several privatization methods, more or less, create more corruption opportunities and that it is crucial to strengthen the banking regulations. The opportunities currently appearing in favor of some regime changes and reforms matter a lot and are very crucial for them to show a major role in elaborating a clear policy and vision necessary for stirring the political willingness through efforts to sensitize the population and mobilize groups, and members of the civil society, in support for the fight against corruption.

\section{Conclusion}

The chronic corruption as occurring in Arab countries following decades of bad governance, poverty, illiteracy, income weakness, absence of strong institutions and in general the State of right and democracy, prevalence of a rent economy, in addition to the impact of socio-cultural beliefs and practices in the Arab countries. The results of our empirical study are highlighting the existence of a statistically significant relationship between the CPI, as a dependent variable on one hand, and HDI, INF and IEF as independent variables on the other hand. Some political regimes, not caring about their populations' interests, have transformed the region resources into structures. Cupid, elites interested in prompt advantages of the corruption and influence trafficking practices, have intervened and presented themselves as standing between politicians and populations, thus monopolizing the State resources to the detriment of the overwhelming majority of the population. In a context characterized by limited resources, corruption constitutes a plague with serious drawbacks on the economic growth, the respect of the fundamental human rights, the quality of life, the supremacy of the law, the credibility of the relevant institutions, as well as the aspiration for democracy. It greatly discourages the investment opportunities and creates distortions with regard to the national and international economic competitiveness. The emerging opportunities available owing to the recently occurring changes affecting certain regimes are of high importance and they help kindling the necessary political willingness through efforts to make the population more sensitive and to mobilize the civil society groups to support the fight against corruption. During the absence of such special circumstances, seven countries out of the countries suffering from an endemic corruption, there are probably certain reformist decision-makers likely to be supported by their partisans for the sake of promoting the general interest of the country, though at a slower rate... We shall know it in the future!

\section{References}

Al-Nasrawi, S. (2008). 'State Security and Human Security: Cases of Intersection, the Iraqi Case,' Arab Human Development Report 2009.

Andving, J. C. et al. (2000). "Research on Corruption: A Policy Oriented Survey," Commissioned by NORAD, Final Report, December, Oslo. 
Awartani, H. (2009). "The Sources of Corruption," Center for International Private Enterprise (CIPE), Development Institute, 15. [Online], [Retrieved March 14, 2013], www.developmentinstitute.org.

Beehner, L. (2007). 'Economic Doldrums in Iraq,' Council on Foreign Relations, 20 juin.

Broadman, H. G. \& Recanatini, F. (1999). 'Seeds of Corruption: Do Market Institutions Matter?,' Washington, D.C.: Poverty Reducation and Economic Management Department; Europe and Central Asia Regional Operations; World Bank;. (I-iv); 1-36.

Cartier-Bresson, J. (1997). 'Quelques Propositions Pour une Analyse de la Corruption en Europe de l'Ouest,' Revue Internationale de Politiques Comparées, 4 (2).

Cartier-Bresson, J. (1999). 'Causes et Conséquences de la Délinquance Financière Grise, le Cas de la Corruption,' in Les Cahiers de la Sécurité Intérieure, Paris.

Cartier-Bresson, J. (2000). 'Economics of Corruption,' OECD Observer, n. 220, April, 25-27.

Cartier-Bresson, J. (2008). “Economie Politique de la Corruption et de la Gouvernance," Paris, éd. L'Harmattan, coll. Ethique économique.

Coolidge, J. \& Rose-Ackerman, S. (1997). "High-Level Rent-Seeking and Corruption in African Regimes: Theory and Cases," World Bank Policy Research Working Paper Series 1780.

Durkheim, E. (1937). 'Les Règles de la Méthode Sociologique,' 1ère édition 1895, préface de la seconde édition, 1901, Paris, Presse Universitaire de France.

Frisch, D. (1996). "Les Effets de la Corruption sur le Développement," in Le Courrier : Afrique, Caraïbes, Pacifique, Union Européenne, 158.

Gerring, J. \& Thacker, S. C. (2005). “Do Neoliberal Policies Deter Political
Corruption?," International Organization, 59 (1), 233-254.

Grey, C. W. \& Kaufmann, D. (1998). "Corruption and Development," Finance \& Development, 35 (1), 7-10.

Heidenheimer, A. J. (1989). Political Corruption, New York, Transaction publishers.

Henri, B. (2000). Au Cœur de la Corruption, 1ère éd., Paris.

Honlonkou, A. (2003). "Corruption, Inflation, Croissance et Développement Humain Durable. Y a-t-il un Lien?," 123 (3), 89-106.

Klitgaard, R. E. (1988). Controlling Corruption, University of California Press.

Klitgaard, R. (1989). "Incentive Myopia," in World Development, 17 (4), 447-459.

Krueger, A. O. (1974). "The Political Economy of the Rent-Seeking Society," American Economic Review, 64 (3), 291303.

Lambsdorff, J. G. (1999). "Corruption in Empirical Research - A Review," Transparency International, Working Paper, November. Berlin., Germany.

Lambsdorff, J. G. (2001). 'Background Paper to the 2001, Corruption Perceptions Index,' Framework Document, Transparency International, Göttingen University, June.

Moody-Stuart, G. (1997). 'Grand Corruption: How Business Bribes Damage Developing Countries,' Oxford, World View Publishing.

Nadgrodkiewicz, A. (2009). 'Les Principes Commerciaux de lutte Contre la Corruption: Renforcer l'intégrité au Moyen-Orient et en Afrique du Nord,' Perspective des Réformes économiques.

Paldam, M. (2002). "The Cross-Country Pattern of Corruption: Economics, Culture and the Seesaw Dynamic," European Journal of Political Economy. 18 (2), 215-240. 
PNUD (2003). "Problématique de la Corruption et Développement Humain," Rapport sur le développement humain Burkina Faso, chapitre 1.

Rocca, J. L. L. (1993). 'La Corruption,' Paris, Syros - Alternatives économiques.

Rose-Ackerman, S. (1979). 'Corruption: A study in Political Economy,' Academic Press.

Talahite, F. (2006). "Les Enjeux de L'évaluation et de la Lutte Contre la Corruption," Communication à la TableRonde: Corruption, Autopsie d'un Fléau', Forum d'el Watan, 14 décembre 2006, Alger, Algérie.

Transparency International (2002). Combattre la Corruption, Enjeux et Perspectives, Paris, éd. Karthala, 360 p.

Transparency International (2003). "Rapport Mondial sur la Corruption," Paris, éd. Karthala; 423 p.

Transparency International (2009). "La lutte Contre la Corruption en Termes Clairs," [Online], [Retrieved December 22, 2013],

http://www.transparency.org/whatwedo/ publications/doc/rep/P60.

UNDP (2002). “Creating Opportunities for Future Generations: Arab Human Development Report," published by UNDP's Regional Bureau of Arab States.

UNDP (2004). 'Towards Freedom in the Arab World,' Arab Human Development Report.

UNDP (2011). “Arab Development Challenges Report 2011: Towards the Developmental State in the Arab Region," Regional Centre for Arab States, Cairo 1191 Corniche El Nil, World Trade Centre Boulac,
Cairo, Egypt, [Retrieved MARCH 12, 2013], http://arabstates.undp.org/.

UNESCO (2009). "Le défi Mondial de l'alphabétisation: Bilan de l'alphabétisation des Jeunes et des Adultes à mi-Parcours de la Décennie des Nations Unies pour l'alphabétisation 2003 - 2012," [Online], [Retrieved December 22, 2013], http://unesdoc.unesco.org/images/0016/0 01631/163170f.pdf.

World Bank (1992). "Governance and Development," Washington D. C. World Bank.

\footnotetext{
${ }^{i}$ A "bribe" is defined as the fact "of offering, promising or granting a pecuniary or other inconvenient advantage, directly or by intermediaries, to a foreign civil servant, to his/her profit or for the benefit of a third party, so that this agent acts or abstains from acting to the execute official functions (offices), to obtain or preserve a market or another inconvenient advantage in the international trade (OECD, 2011).
} 
iiTI some times defines corruption broadly «as the abuse of entrusted power for private gain» (TI, 2002).

iiiFrom the precedent formula: corruption = monopoly position + to be able to discretionary responsibility (International Monetary Fund (IMF), 1998). This formula translates well the idea of Banfield (1958), that of Rose-Ackerman (1979) and Klitgaard (1988), who assert that corruption raises the problem of information asymmetry. In such a context, control of the phenomenon depends on the monitoring costs which the center of decision (political leaders) is ready to support.

ivThese costs are measurable. The World Bank, for example, estimates that the financial volume of this plague amounts to 1 trillion of dollars in 2002. Available on, http:// live.banquemondiale.org/la-corruption.

vCorruption of a state employee by a migrant worker in irregular situation which "buys" a residence-permit can be defined with similarly concepts as the purchase of a state employee with the aim of the allowance (allocation) of a public contract? Does corruption make more, or less, problems in Peru than in Japan? (Bresson, J-C., 1992).

viThe poverty threshold, or poverty lines, is the minimum level of income deemed adequate in a given country. The percentage of the population living below the national poverty line for example: in Sudan 46.5 \% in 2008, in the West Bank and Gaza 21.9 \% in 2009; in Egypt $22 \%$ in 2008, in Mauritania 42.0 \% in 2008; Iraq $22.9 \%$ in 2007. Tunisia 23,3 \% in 2005 while it is $34.8 \%$ in 2005 in the Yemen. Available on, http://donnees.banquemondiale.org/indicateur/NY.GDP.DEFL.KD.ZG.

viiThe Gini-revenu measures the extent to which the distribution of income (or consumption expenditure) among individuals or households within an economy deviates from a perfectly equal distribution. A value 0 indicates an absolute equality, a value equal to 100 an absolute disparity. These indicators are of the order of: the West Bank and Gaza, 38.7 in 2006; the Comoros Isles in 2004, 64.3; Iraq, 30.9 in 2007 and Jordan 37.7 in 2006, (World Bank, ibid).

viiiThe ease of doing-business index ranks economies from 1 to 183 , with a first place being the best. A high ranking (a low numerical rank) means that the regulatory environment is conducive to business operation. The index averages the country's percentile rankings on 10 topics covered in the World Bank's Doing Business. The ranking on each topic is the simple average of the percentile rankings on its component indicators. In 2012, the classification of some Arab countries has been as follows : Algeria 152; Comoros 158; Djibouti 171; Iraq 165; Kuwait 82; Lebanon 115; Mauritania 167; Syrian Arab Republic 144. 